\title{
Utility of fine needle aspiration cytology in metastatic lymph nodes
}

\author{
Ghartimagar $\mathrm{D}^{1}$, Ghosh $\mathrm{A}^{1}$, Ranabhat $\mathrm{S}^{1}$, Shrestha $\mathrm{MK}^{2}$, \\ Narasimhan $\mathrm{R}^{1}$, Talwar $\mathrm{OP}^{1}$
}

${ }^{1}$ Department of Pathology, Manipal Teaching Hospital and Manipal College of Medical Sciences, Pokhara, Nepal

${ }^{2}$ Department of Radiology, Manipal Teaching Hospital and Manipal College of Medical Sciences, Pokhara, Nepal

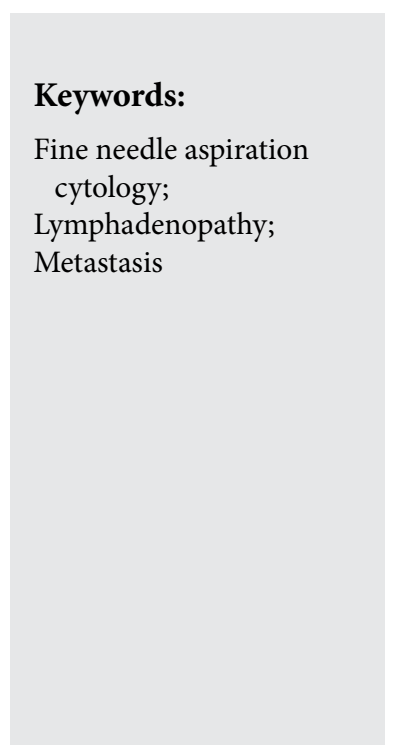

\section{ABSTRACT}

Background: Fine needle aspiration cytology is a reliable as well as an inexpensive diagnostic method. It is suitable for the developing countries like Nepal for the diagnosis of lymphadenopathy at any approachable site. Fine needle aspiration cytology not only confirms the presence of metastatic disease but also, in most cases, gives the clue regarding the origin of the primary tumor. The aim of the study was to find out the cytological diagnosis of metastatic lymph node lesions.

Materials and Methods: A combined prospective and retrospective study was done of all metastatic lymph node lesions (including both superficial and deep nodes) reported in Department of Pathology, Manipal Teaching Hospital, Pokhara from January 2005 to Deceember 2010.

Results: A total of 4180 cases of fine needle aspiration cytology were carried out of which 508 cases were of lymph node. Cytology results were unsatisfactory in 58 specimens (12\%), "reactive" or "infective" in 347 specimens (68\%), positive for metastasis in 93 specimens (18\%) and hematolymphoid malignancies include 10 cases $(2 \%)$. The most common site was anterior and posterior triangles cervical nodes. The most common malignancy was adenocarcinoma, seen in 62 cases $(67 \%)$, followed by metastatic squamous cells carcinoma (14 cases, $15 \%)$.

Conclusion: Fine needle aspiration cytology of lymphadenoathy is a useful tool in diagnosing metastatic lesions with good certainty.

\section{INTRODUCTION}

The use of Fine Needle Aspiration Cytology (FNAC) for the diagnosis of metastatic malignancies in the lymphnode is a well established method. ${ }^{1}$ Lymphadenopathy in an adult patient may be the first presenting clinical sign

\footnotetext{
Correspondence:

Dr. Dilasma Ghartimagar, $M D$

Lecturer, Department of pathology

Manipal teaching hospital, Pokhara, Nepal.

E-mail:dilasmagm@hotmail.com
}

of non-hematologic malignancy. FNAC not only confirms the presence of metastatic disease, but also gives the clue regarding the nature and origin of primary malignancy. FNAC is useful for the detection of recurrence and new metastasis.

In developing country like Nepal, infective lymphadenopathy is quite common, mostly due to high prevalence of tuberculosis. However, still a large percentage of cervical lymhadenopathy in adults turn out to be malignant. Cysts 
(congenital or acquired), abscesses, benign and malignant tumors may mimic lymph node metastasis, especially with a case of known tumor. ${ }^{2}$ Cystic metastasis or aspirate of low grade malignancies compose most of false negative cases. ${ }^{3,4}$

This procedure is cheap, easily repeatable and well tolerated by the patients and can be performed on outpatient basis. ${ }^{5}$

The aim of the study was to find out the cytological diagnosis of metastatic lymph node lesions.

\section{MATERIALS AND METHODS}

This is a combined prospective and retrospective study of all metastatic lymph node on FNAC samples reported over a period of 6 years from January 2005 to December 2010. This study was carried out in the Department of Pathology, Manipal Teaching Hospital.

All FNACs were performed using a 23 gauge needle. An average of 2 passes and a minimum of 4 slides were made, Slides were routinely stained with both Giemsa and Papanicolaou (PAP) stains and wherever applicable, PAS stain was used. In case of deep seated lesions, Ultrasonography (USG) guided FNAC was performed. Smears showing adequate cellular material was considered as "satisfactory" and were reported as "positive for metastasis" with further subtyping wherever possible. All the clinical and pathological data were collected and analyzed using SPSS11 software.

\section{RESULTS}

Out of total 4180 cases of FNAC, 508 cases (12\%) were of lymph nodes. Among these, there were a total of 93 nodes reported as "positive for metastasis" accounting for $18 \%$ of all lymph node FNACs and $2 \%$ of all FNAC cases. Other lymph nodes were reported as "reactive" and "infective" in 347 cases (68\%), "positive for metastasis" in 93 cases (18\%), "hematologic malignancy" in 10 cases (2\%) and "unsatisfactory" in 58 smears (12\%). The causes of "unsatisfactory smears" were scant cellular yield, obscuring blood, and also thick cohesive clusters. The metastatic lymph nodes were located in anterior and posterior cervical triangles, supraclavicular area, axilla, abdomen and inguinal region. The most common sites were the cervical triangles comprising 45 cases followed by 30 cases from supraclavicular nodes.

The age of the patient ranged from 24 to 86 years with a mean of 60.4 years. The incidence was seen to peak at the age range above 60 years showing 57 cases (61\%), followed by 31 cases (34\%) in the age group 40 to 59 years. There were 5 cases (5\%) below 40 years of age. The incidence of metastasis were more in female (54 cases, $58 \%$ ) as compared to male (39 cases, $42 \%$ ) with male to female ratio 1:1.25.

The most common subtype of metastatic malignant tumor was adenocarcinoma and was observed in 62 cases. The metastasis had occurred form primary carcinomas in lung, stomach, colon and rectum. This was followed by squamous cell carcinoma (14 cases). The primary sites of these squamous cell carcinoma included tongue, alveolus, buccal mucosa and palate. Nodes were found to be positive in 2 known primary thyroid carcinoma and 3 known primary breast carcinoma patients. The 3 breast carcinoma cases had already known primary, hence they were kept under breast carcinoma in Table1. Two patients showed metastasis in cervical nodes of small cell carcinoma of lung. In 8 cases lung masses were seen in radiology and FNAC from accessible lymph nodes were reported as "non small cell carcinoma metastasis" as further subtyping was not possible. Malignant melanoma metastasis in cervical lymph node and inguinal lymph nodes was seen in 1 case each. Various subtypes of metastatic lymph node lesions and site of distribution with percentage are shown in Table 1\&2.

\section{DISCUSSION}

FNAC is of considerable value in disease staging and documentation of metastasis in known primary and occult tumors. FNAC is a reliable diagnostic tool for lymphadenopathy in adult patients who are suspected for malignancy as it has less complication, is a simple invasive procedure and can be repeated easily. More than $90 \%$ of lymph node metastasis are diagnosed by initial aspiration. ${ }^{2}$ Common metastatic tumors include malignancies from thyroid, respiratory system, gastrointestinal tract, male and

Table 1: Distribution of different pathological subtypes of metastasis

\begin{tabular}{llcc}
\hline S.N. & Pathological Subtypes & No. of cases & Percentage \\
\hline 1 & Adenocarcinoma & 62 & $67 \%$ \\
\hline 2 & Squamous cell carcinoma & 14 & $15 \%$ \\
\hline 3 & Breast ductal carcinoma & 3 & $3 \%$ \\
\hline 4 & Papillary carcinoma thyroid & 2 & $2 \%$ \\
\hline 5 & Small cell carcinoma & 2 & $2 \%$ \\
\hline 6 & Non small cell carcinoma & 8 & $9 \%$ \\
7 & Malignant melanoma & 2 & $2 \%$ \\
\hline & Total & $\mathbf{9 3}$ & $\mathbf{1 0 0 \%}$ \\
\hline
\end{tabular}

Table 2: Distribution of number of cases according to sites of lymphadenopathy

\begin{tabular}{lcc}
\hline Sites of Lymphadenopathy & No. of cases & Percentage \\
\hline Cervical triangles & 45 & $48 \%$ \\
\hline Supraclavicular & 30 & $32 \%$ \\
\hline Axillary & 11 & $12 \%$ \\
\hline Abdominal & 1 & $1 \%$ \\
\hline Inguinal & 6 & $7 \%$ \\
\hline Total & $\mathbf{9 3}$ & $\mathbf{1 0 0 \%}$ \\
\hline
\end{tabular}


female genital tracts..$^{5}$

In the present study, adenocarcinoma was the most common metastatic tumor. In well differentiated adenocarcinoma, it showed cells with acinar and occasionally papillary arrangement and also singly scattered. The individual cells are usually large, cuboidal to columnar with moderate amount of cytoplasm and pleomorphic nuclei with prominent nucleoli (fig.1). Cells even show vacuolated cytoplasm indicating intracellular mucin secretion. Background may show pink homogenous mucoid material if the mucin content of the tumor is high.

In other studies also the most common metastatic subtype were adenocarcinoma. ${ }^{6,7}$ However, often it becomes difficult to distinguish between adenocarcinoma and poorly differentiated squamous cell carcinoma when the cell clusters show thick nuclear membrane and prominent nucleoli. ${ }^{89}$ Cells with abundant clear cytoplasm also raise a suspicion of metastasis from the renal tumors. ${ }^{10}$

In our study 2 cases of papillary thyroid carcinoma showed

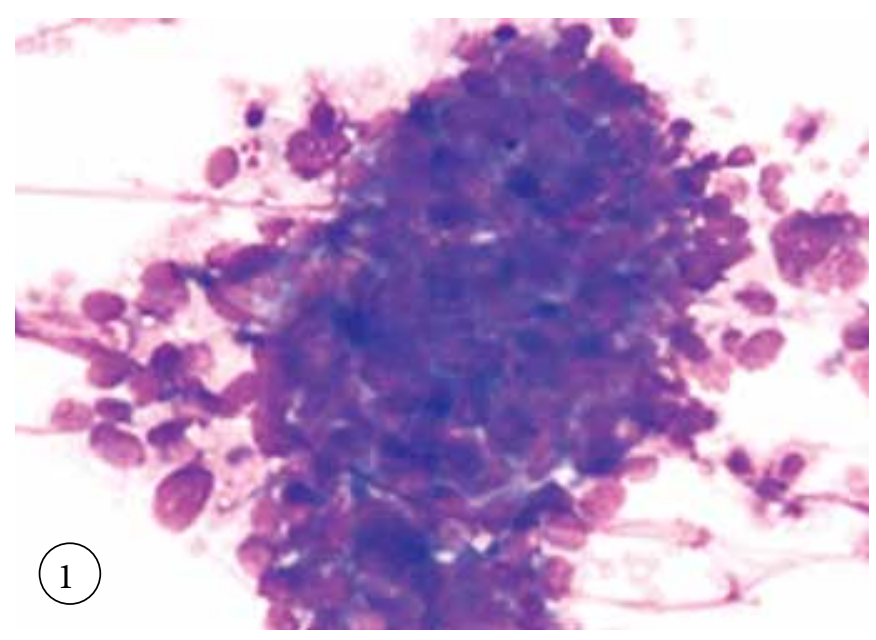

Figure 1: Cytology smear showing metastatic clusters of adenocarcinoma (Giemsa stain, X40).

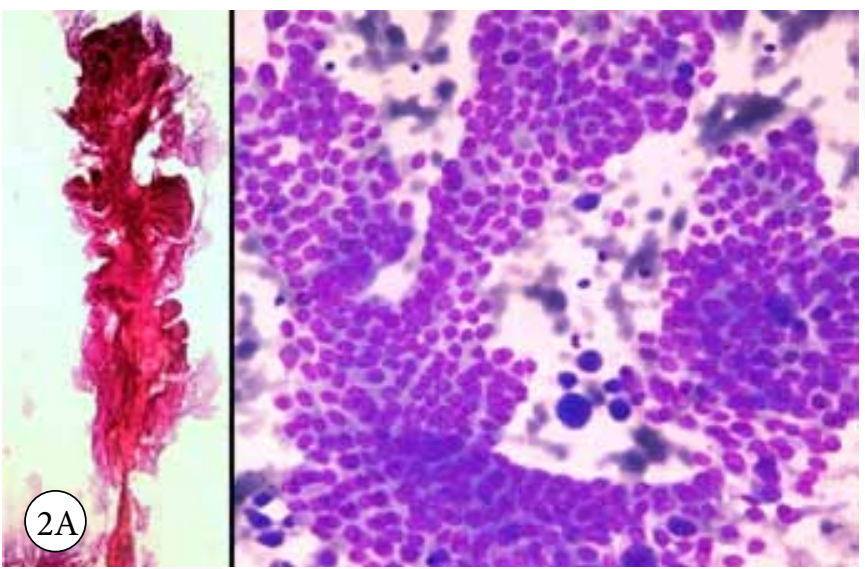

Figure 2A: Cytology smear showing papillary clusters with central fibrovascular core. (PAP stain, X40). metastatic deposit in lymph nodes; where the cell clusters were in papillary pattern with central fibrovascular core along with the characteristic vesicular nuclei with nuclear grooving and intranuclear inclusion (Fig.2A and B). Some of the follicular cells demonstrated features of squamoid differentiation.

Metastatic squamous cell carcinoma was the second most common entity in our study. Tumor cells are seen mostly in sheets and singly scattered. The cells had dense cytoplasm with hyperchromatic nuclei in Giemsa stain and the cells show cynophilic or orangeophilic cytoplasm with pyknotic nuclei in PAP stain (Fig.3). In well differentiated squamous cell carcinoma, the tumor cells show individual cell keratinization. ${ }^{10,11}$ The tumor cells often show necrotic material in the background. So in case of scanty cellularity with abundant necrotic material, a careful search for the tumor cells is required. Other studies showed squamous cell carcinoma as the most common metastatic tumor. ${ }^{10,12}$

In our study, metastatic ductal carcinoma was seen in 3 cases where all the female patients presented with breast lumps.

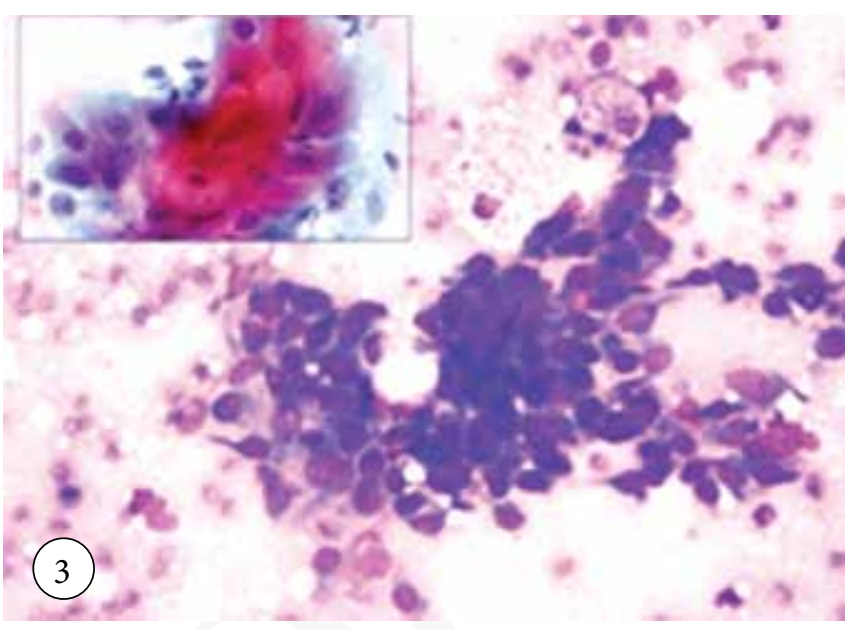

Figure 3: Cytology smear showing cluster of squamous cells carcinoma with dense cytoplasm (Giemsa stain, X40), Inset shows dense intracellular keratin formation (PAP stain, X100).

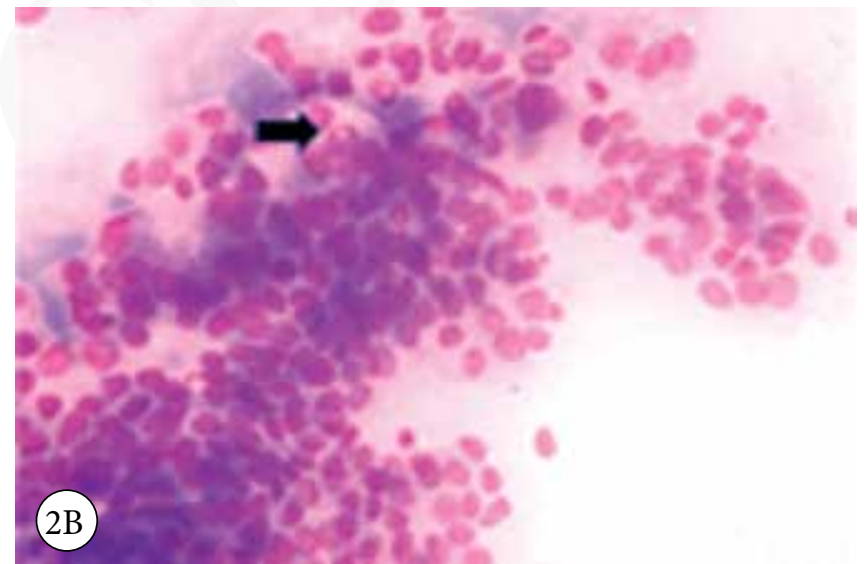

Figure 2B: Cytology smear showing intranuclear inclusion. (Giemsa stain, X100). 
Two cases had axillary lymphadenopathy while 1 case had axillary, supraclavicular and cervical lymphadenopathy. The smears yielded high cellularity with several loose clusters of tumor cells. Malignant ductal cells have moderate to abundant cytoplasm with pleomorphic nuclei and prominent single to multiple nucleoli (fig.4). Tumor giant cells were also noted in one case.

Metastatic small cell carcinoma was seen in 2 cases where the patient had suspicious mass lesion in the lung. Here the cells have scant cytoplasm with nuclei two to three times larger than small lymphocytes. Nuclei usually demonstrate the classical "salt and pepper" chromatin with indistinct nucleoli and frequent moulding. Streaking artefact along with karyorrhectic debris are seen in the background. ${ }^{11,13}$ Sometimes, these background findings may make it difficult to differentiate from lymphoma where clinical findings (more generalised lymphadenopathy) may be helpful to differentiate. ${ }^{10}$

Melanomas can be seen anywhere in the body for example eyeballs, head, neck, great toe to name a few, and it is notorious to metastasize to any, specifically cervical or inguinal nodes. Our study showed 2 cases of metastatic melanoma, 1 each in cervical and inguinal lymph nodes. These smears showed discohesive pleomorphic cells with binucleate or multinucleate forms. The nuclei are large with characteristic prominent 1-2 macronucleoli. Intra and extracellular mealanin pigment were seen both cases (fig. 5). Contrary with that other studies have observed melanin pigment in $25 \%$ of melanoma metastasis cases. ${ }^{9,14}$

\section{CONCLUSION}

Cytology evaluation along with proper clinico-radiological correlation are quite useful in diagnosing metastasis with good degree of certainty. To conclude, in developing countries, like ours, FNAC is a cheap quick and reliable method to assess suspicious lymphadenopathy.

\section{REFERENCES}

1. Steel BL, Schwartz MR, Ramzy I. Fine needle aspiration biopsy in the diagnosis of lymphadenopathy in 1103 patients. Role, limitations and analysis of diagnostic pitfalls. Acta Cytol 1995;39:76-81.

2. Ustun M, Risberg B, Davidson B, Berner A. Cystic Change in metastatic lymph Nodes: A common diagnostic pitfall in Fine-Needle Aspiration Cytology. Diagn Cytopathol 2002;27:387-92.

3. Kusum V, Mandal S, Kapila K. Cystic change in lymph nodes with metastatic squamous cell carcinoma. Acta Cytol 1995;39:478-80.

4. Monchik JM, De Petris G, De Crea C. Occult papillary carcinoma of the thyroid presenting as a cervical cyst. Surgery 2000;129:429-32.

5. Thomas Jo, Adeyi D, Amanguno H. Fine-needle aspiration in the management of peripheral lymphadenopathy in a developing country. Diagn Cytopathol 1999;21:159-62.

6. Schafernak KT, Kluskens LF, Ariga R, Reddy VB, Gattuso P. Fineneedle aspiration of superficial and deeply seated lymph nodes on patients with and without a history of malignancy: review of 439 cases. Diagn Cytopathol 2003;29:315-9.

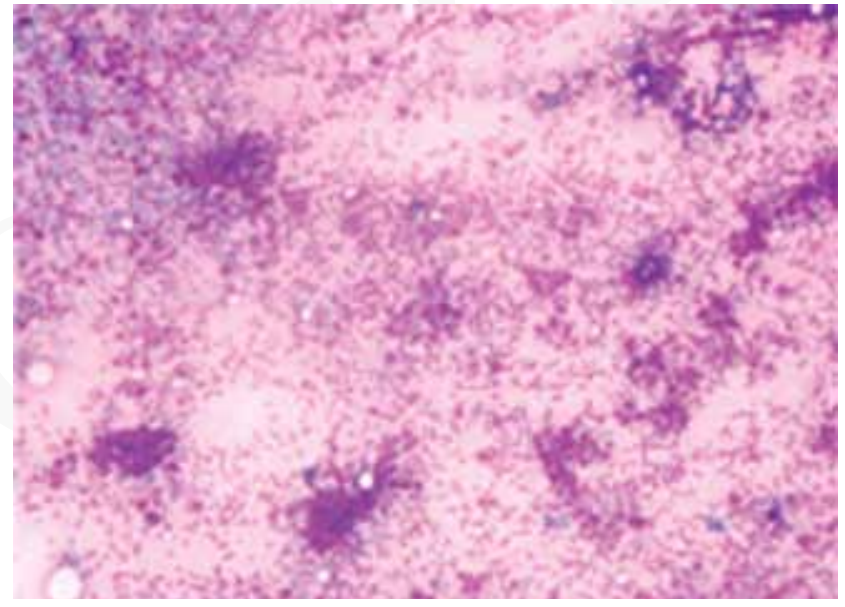

Figure 4: Smear showing malignant ductal cells with lymphoid cells in the background (Giemsa stain, X40).

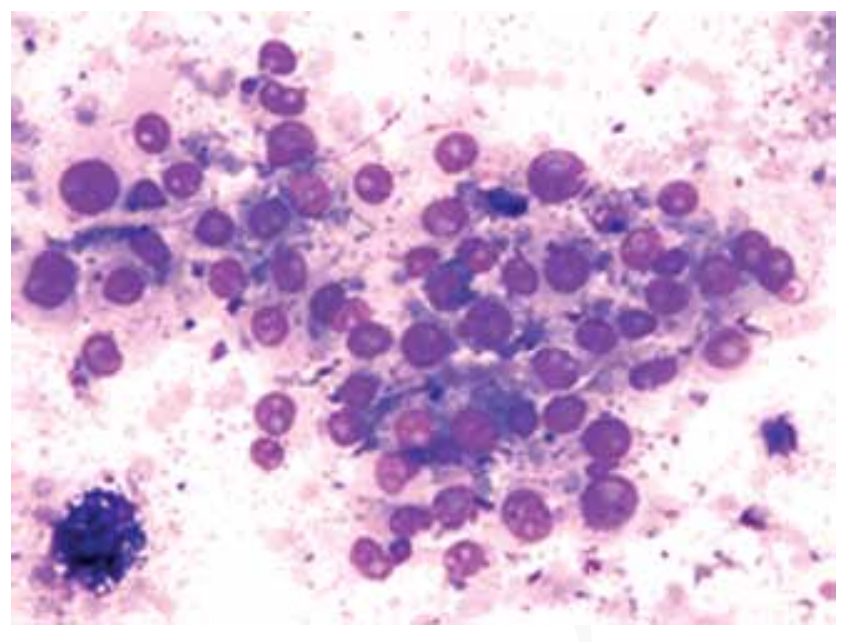

Figure 5: Smear showing metastatic malignant melanoma with melanin pigments. (Giemsa stain, X40).

7. Nasuti JF, Mehrotra R, Gupta PK. Diagnostic value of fine-needle aspiration in supraclavicular lymphadenopathy: a study of 106 patients and review of literature. Diagn Cytopathol 2001;25:351-5.

8. El Hag IA, Chiedozi LC, al Reyees FA, Kollur SM. Fine needle aspiration cytology of head and neck masses. Seven years' experience in a secondary care hospital. Acta Cytol. 2003;47:387-92.

9. Fulciniti F, Califano L, Zupi A, Vetrani A: Accuracy of Fine needle aspiration biopsy in head and neck tumours. J Oral Maxillofac Surg 1997;55:1094-7

10. Bagwan IN, Kane SV, Chinoy RF. Cytologic Evaluation of the Enlarged Neck Node: FNAC Utility in Metastatic Neck Disease. The Internet Journal of Pathology. 2007; 6(2).Available in URL: http:// www.ispub.com/journal/the_internet_journal_of_pathology/current. html

11. Singh HK, Silverman JF. Lung, chest wall and pleura. In : Orell SR, Sterrett GF, Whitaker D, editor. Fine Needle Aspiration Cytology.4th ed. Elsevier: Churchill livingstone; 2005. pp245-9.

12. Chute DJ, Stelow EB. Cytology of head and neck squamous cell carcinoma variants. Diagn Cytopathol.2010;38:65-80.

13. Bedrossian CMW, Davila RM: Cytologic examination and fine needle aspiration. In Saldana MJ(ed.): Pathology of pulmonary disease . Lippincott -Raven, Philadelphia,1994. pp35

14. Schwarz R, Chan NH, MacFarlane JK: Fine needle aspiration cytology in the evaluation of head and neck masses. Am J Surg 1990;159:482-5. 